\title{
In Vitro Antibacterial Activity of a 7-O- $\beta$-D-glucopyranosyl- nutanocoumarin from Chaptalia nutans (Asteraceae)
}

\author{
Maria da Conceição Torrado Truiti, Maria Helena Sarragiotto*, Benício Alves de Abreu \\ Filho** $^{* *}$ Celso Vataru Nakamura**, Benedito Prado Dias Filho**/+
}

\begin{abstract}
Departamento de Farmácia e Farmacologia *Departamento de Química**Departamento de Análises Clínicas, Universidade Estadual de Maringá, Campus Universitário, Avenida Colombo 5790, 87020-900 Maringá, PR, Brasil
\end{abstract}

Ethanolic crude extracts from the roots of Chaptalia nutans, traditionally used in Brazilian folk medicine, were screened against Staphylococcus aureus, Escherichia coli, and Pseudomonas aeruginosa by using the disk diffusion test technique. S. aureus with $14 \mathrm{~mm}$ inhibition zone was considered susceptible. E. coli and P. aeruginosa without such a zone were considered resistant. As a result of this finding, the ethanolic crude extract was fractionated on silica gel column chromatography into five fractions. The ethyl acetate fraction was active against $\mathrm{S}$. aureus and Bacillus subtilis. Further column chromatography separation of the ethyl acetate fraction afforded 30 fractions, which were assayed against S. aureus. Fractions 16 and 17 showed inhibition zones with $\mathrm{S}$. aureus, indicating the presence of active compounds, and were subjected to purification by repeated preparative thin layer chromatography. The pure compound 7-O- $\beta$-D-glucopyranosyl-nutanocoumarin inhibited $\mathrm{B}$. subtilis and $\mathrm{S}$. aureus at concentrations of $62.5 \mu \mathrm{g} / \mathrm{ml}$ and $125 \mu \mathrm{g} / \mathrm{ml}$, respectively. The antibacterial property of C. nutans appears to have justified its use for the treatment of wounds, which are contaminated through bacterial infections.

Key words: Chaptalia nutans - Asteraceae - traditional medicine - antibacterial activity - 7-O- $\beta$-D-glucopyranosylnutanocoumarin

Chaptalia nutans (L.) Polak (Asteraceae), known as "língua-de-vaca-miúda" and "costa-branca", is a herbaceous perennial plant widely distributed in tropical America (Barroso 1986). In South America the leaves, roots, and stems of this plant have been used in folk medicine for the treatment of fever, headache, skin diseases, herpes and as a diuretic (Reitz 1973, Lorenzi 1991, Martins et al. 1994). The most popular preparation is a decoction of the roots which is employed for soaking sore feet (Morton 1981, Panizza 1997). Recently, the anti-inflammatory properties of aqueous extracts from the leaves of this plants were studied using the carregeenan induced rat paw edema model (Badilla et al. 1999). This paper reports the results of a general hippocratic screening, the toxicity tests and the experimental validation of the anti-inflammatory activity of five plants used empirically by the Costa Rica population as anti-inflammatory remedies.

Bax et al. (2000) have reported that global antibacterial resistance is becoming an increasing public health problem. Bacterial resistance to almost all available antibacterials has been recorded. According to these authors, the pharmaceutical industry and fledgling biotechnology companies are intensifying efforts to discover novel antibac-

This study was supported by grants from the Conselho Nacional de Desenvolvimento Científico e Tecnológico, CNPq, Capacitação de Aperfeiçoamento de Pessoal de Nível Superior, Capes, and Programa de Pós-graduação em Ciências Farmacêuticas, Universidade Estadual de Maringá.

${ }^{+}$Corresponding author: Fax +55-44-261.4490. Email: bpdfilho@uem.br

Received 10 May 2002

Accepted 21 November 2002 terials in attempts to overcome bacterial resistance.

The use and search for drugs and dietary supplements derived from plants have accelerated in recent years (Cowan 1999). Ethnopharmacologists, botanists, microbiologists, and natural-products chemists are combing the Earth for phytochemicals and "leads" which could be developed for the treatment of infectious diseases. According to this author, while 25 to $50 \%$ of current pharmaceuticals are derived from plants, none are used as antimicrobials.

In the present study the in vitro antibacterial activity of the separated fractions of ethanolic extracts from the roots of $C$. nutans and of the bioassay-guided isolated 7O- $\beta$-D-glucopyranosyl-nutanocoumarin, a new 5methylcoumarin, is described.

\section{MATERIALS AND METHODS}

Plant material - The roots were collected in January 1994, in Maringá, Paraná, Brazil. A voucher specimen (no. 3361) is deposited at the herbarium of the Universidade Estadual de Maringá.

Microorganisms and growth conditions - The following microorganisms were used for detecting antibacterial compounds: Escherichia. coli ATCC 25922, Staphylococcus aureus ATCC 25923, Pseudomonas aeruginosa ATCC 15442 and Bacillus subtilis ATCC 6623. S. aureus penicillin-susceptible and -resistant strains were obtained from local clinical microbiology laboratories. Culture of these bacteria were grown in nutrient broth (Difco Laboratories, Detroit, $\mathrm{MI}$ ) at $37^{\circ} \mathrm{C}$ and maintained on nutrient agar slants at $4^{\circ} \mathrm{C}$.

Reference antibiotics - The following reference antibiotics were purchased from Sigma Chemical Co. (St. Louis, $\mathrm{MO}$ ): chloramphenicol, vancomycin, tetracycline and penicillin. 
Isolation of the active compound - The air-dried and powdered roots of $C$. nutans were successively extracted at room temperature with $n$-hexane and ethanol. In the bioassay-guided fractionation, the ethanol crude extract of the roots of was screened against $S$. aureus, E. coli and $P$. aeruginosa by using the disk diffusion test technique. The ethanol active extract was submitted to column chromatography on silica gel eluted with a hexane, hexane/ ethyl acetate (50:50), ethyl acetate, ethyl acetate/methanol (50:50) and then methanol. Further separation of the active ethyl acetate fraction by column chromatography afforded 30 fractions, which were assayed against $S$. aureus by bioautography as described below. Purification of the active fractions 16 and 17 by repeated preparative thin layer chromatography (TLC), followed by bioassay for the pure isolated compounds was performed as previously described (Truiti \& Sarragiotto 1998).

Preparative thin layer chromatography - Silicagel $\mathrm{GF}_{254}$ plates, $20 \times 20 \mathrm{~cm}, 1 \mathrm{~mm}$ thick, were used. Fractions of the ethyl acetate extract were applied and the chromatogram developed using cloroform-methanol (4:1) as solvent. TLC plates were run in duplicate and one set was used as the reference chromatogram. Spots and bands were visualized by UV irradiation ( 254 and $366 \mathrm{~nm}$ ) and $\mathrm{H}_{2} \mathrm{SO}_{4}$ spray reagent. The other set was used for bioautography.

Bioautography - Chromatogram developed as described above were placed in sterile glass dish with cover and a inoculum of $S$. aureus containing $10^{6} \mathrm{CFU} / \mathrm{ml}$ in molten Mueller Hinton agar was distributed over the plates. After solidification of the medium, the TLC plate was incubated overnight at $37^{\circ} \mathrm{C}$. Inhibition zones indicated the presence of active compounds.

Susceptibility testing - For the disk diffusion test, four $6.35 \mathrm{~mm}$ diameter paper disks (no. 2, Whatman) are placed in the inverted lid of one of the assay plates and tenfold serial dilutions $(0.02 \mathrm{ml})$ of the sample $(1 \mathrm{mg})$ are placed on each of the four disks. Control disks contained $0.02 \mathrm{ml}$ of the DMSO solvent were included in the assay. The disks were placed on Mueller-Hinton (Difco) plates, surface spread with $0.1 \mathrm{ml}$ of logarithmic phase bacteria cultures (ca. $10^{8} \mathrm{CFU} / \mathrm{ml}$ ). After 16 to $18 \mathrm{~h}$ of incubation at $37^{\circ} \mathrm{C}$, the plates were examined, and the diameters of the zones of complete inhibition were measured to the nearest whole millimeter. Strains with an inhibition zone were considered susceptible to samples; those without such a zone were considered resistant. For the minimal inhibitory concentration (MIC) (NCCLS 1997a, b) twofold serial dilutions of the all samples and reference antibiotics were made in Mueller-Hinton broth (Merck S.A., São Paulo). Each inoculum was prepared in the same medium at a density adjusted to a 0.5 McFarland turbidity standard $\left[10^{8}\right.$ colony-forming units (CFU)/ml] and diluted 1:100 for the broth microdilution procedure. Microtiter trays were incubated at $37^{\circ} \mathrm{C}$ and the MICs were recorded after $24 \mathrm{~h}$ of incubation. Two susceptibility endpoints were recorded for each isolated. The endpoint MIC is the lowest concentration of compounds at which the microorganism tested does not demonstrate visible growth. Minimal bactericidal concentrations (MBCs) were determined by subculturing $10 \mu \mathrm{l}$ from each negative well and from the positive growth control. MBCs were defined as the lowest concentration yielding negative subcultures or only one colony.

\section{RESULTS AND DISCUSSION}

The dried roots of $C$. nutans were extracted successively with $n$-hexane and ethanol. Screening tests of ethanolic crude extract against $S$. aureus, E. coli, and $P$. aeruginosa by using the disk diffusion test technique are given in Table I. S. aureus with a $14 \mathrm{~mm}$ inhibition zone was considered susceptible. E. coli and P. aeruginosa without such a zone were considered resistant.

\section{TABLE I}

Antimicrobial activity of ethanolic crude extract of the roots of Chaptalia nutans as determined by diffusion technique on solid media (paper disks)

\begin{tabular}{lccc}
\hline & \multicolumn{3}{c}{ Concentrations $(\mu \mathrm{g})$} \\
\cline { 2 - 4 } Microorganism & 48 & 24 & Control \\
\cline { 2 - 4 } Staphylococcus aureus & \multicolumn{3}{c}{ Inhibition zone $(\mathrm{mm})$} \\
Pseudomonas aeruginosa & 0 & 12 & 0 \\
Escherichia coli & 0 & 0 & 0 \\
\hline
\end{tabular}

As a result of this finding, the ethanolic crude extract was fractionated on silica gel CC into five fractions. The ethyl acetate fraction was active against $S$. aureus and $B$. subtilis with MICs of $250 \mu \mathrm{g} / \mathrm{ml}$ and $125 \mu \mathrm{g} / \mathrm{ml}$, respectively (Table II). The hexane, hexane/ethyl acetate (50:50), ethyl acetate/methanol (50:50), and methanol fractions showed no activity against the organisms tested. Similar results were obtained by using the disk diffusion test technique (data not shown). Further separation of the ethyl acetate fraction by column chromatography afforded 30 fractions, which were assayed for $S$. aureus by bioautography. Fractions 16 and 17 showed inhibition zones against S. aureus, indicating the presence of active compounds, and were subjected to purification by repeated preparative TLC. The pure isolated compound was assayed against the microorganisms presented in Table III. The pure compound that showed antibacterial activity was identified as 7-O- $\beta$-D-glucopyranosyl-nutanocoumarin (chemical structure in the Figure) based on its spectroscopic data (Truiti \& Sarragiotto 1998).

\section{TABLE II}

Minimal inhibitory concentration (MIC) of the fractions obtained from the ethanol crude extract by chromatography column on silica gel

\begin{tabular}{lcc}
\hline & \multicolumn{2}{c}{ MIC $(\mu \mathrm{g} / \mathrm{ml})$} \\
\cline { 2 - 3 } Fractions & Staphylococcus aureus & Bacillus subtilis \\
\hline Ethyl acetate & 250 & 125 \\
Hexane & $>1000$ & $>1000$ \\
Hexane/ethyl acetate & $>1000$ & $>1000$ \\
Ethyl acetate/methanol & $>1000$ & $>1000$ \\
Methanol & $>1000$ & $>1000$ \\
\hline
\end{tabular}


Table III summarizes the MICs and MBCs of the purified active compound for all bacterial tests. The 7-O- $\beta$-Dglucopyranosyl-nutanocoumarin inhibited $B$. subtilis and S. aureus at concentrations of $62.5 \mu \mathrm{g} / \mathrm{ml}$ and $125 \mu \mathrm{g} / \mathrm{ml}$, respectively. The minimal bactericidal concentrations were within one twofold dilution of the MICs for this organisms. The endpoints were not reached for $E$. coli and $P$. aeruginosa $(>1000 \mu \mathrm{g} / \mathrm{ml})$. The MICs of the reference drugs used in this study were similar to those presented in other reports.

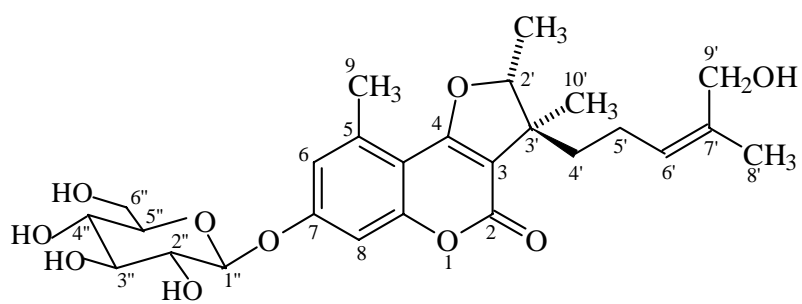

Chemical structure of 7-O- $\beta$-D-glucopyranosyl-nutanocoumarin isolated from Chaptalia nutans.

TABLE III

Minimal inhibitory concentration (MIC) and minimal bactericidal concentration (MBC) of 7-O- $\beta-\mathrm{D}-$ glucopyranosyl-nutanocoumarin

\begin{tabular}{lcc}
\hline Microorganisms & $\mathrm{MIC}(\mu \mathrm{g} / \mathrm{ml})$ & $\mathrm{MBC}(\mu \mathrm{g} / \mathrm{ml})$ \\
\hline Bacillus subtilis & 62.5 & 125 \\
Staphylococcus aureus & 125 & 250 \\
Pseudomonas aeruginosa & $\geq 1000$ & $\geq 1000$ \\
Escherichia coli & $\geq 1000$ & $\geq 1000$ \\
\hline
\end{tabular}

Antimicrobial activity for the aerial parts extracts of $C$. nutans, and for the isolated compound $4-\mathrm{O}-\beta$ glucopyranosyl-5-methylcoumarin have been previously reported (Heinrich et al. 1991). Under the conditions employed here, aerial parts extracts of $C$. nutans, and the isolated compound 4-O- $\beta$-glucopyranosyl-5-methylcoumarin were inactive (MIC $>1000 \mu \mathrm{g} / \mathrm{ml}$ ) for all the microorganisms tested (data not shown).

Because penicillin-resistant $S$. aureus (PRSA) strains seemed to be more sensitive to isolated compound than penicillin-susceptible $S$. aureus (PSSA), we compared the antibacterial activity of 7-O- $\beta$-D-glucopyranosylnutanocoumarin for PRSA and PSSA strains from clinical specimens. The MICs at which 50 and $90 \%$ of the strains are inhibited ( $\mathrm{MIC}_{50}$ and $\mathrm{MIC}_{90}$, respectively), as well as the range of MICs of tested bacteria, are listed in Table IV. The activity of 7-O- $\beta$-D-glucopyranosyl-nutanocoumarin against PRSA was significantly higher than that for PSSA. This is particularly noteworthy because the majority of penicillin-resistant staphylococci are often resistant of many other unrelated drugs.

The incidence of severe nosocomial infections caused by gram-positive cocci has increased in the last decades. This increase has been accompanied by the resistance of these microorganisms to multiple antimicrobials (Villanova et al. 1989). The recent emergence of bacterial infections and resistant strains has stimulated the investigation of plants used in traditional medicine as a source of new antiinfective agents.

The use of medicinal plants in the world, and especially in South America, contributes significantly to primary health care. Leal-Cardoso and Fonteles (1999) have reviewed the pharmacological studies made with essential oils from 15 species of aromatic plants from the Northeast of Brazil. These studies have dealt with the effect of these oils on muscle contraction and with their antispasmodic, analgesic, anti-inflammatory, anticonvulsant and antibacterial activity. In this work, the essential oils of the medicinal species have shown activity coherent with the use of these plants in folk medicine.

The beneficial medicinal effects of plant materials typically results from the combination of secondary products present in the plant. Research in the pharmacognosy of medicinal plants has also involved assays of bio-activity, identification of potential modes of action, and target sites for active phytomedicinal compounds. Recently, Nakamura et al. (1999) reported the antibacterial activity of both the essential oil and a purified eugenol of Ocimum gratissimum, traditionally used in folk medicine to treat different diseases, e. g. upper respiratory tract infections, diarrhoea, skin diseases, pneumonia, and also as a treatment for cough, fever and conjunctivitis. More recently, Alves et al. (2000) have reported the screening of 60 medicinal plant species from the Brazilian savanna that could contain useful compounds for the control of infectious diseases. According to these authors, more than $60 \%$ of plant species afforded extracts with some degree of activity, particularly against the gram-positive bacteria $S$. aureus and $B$. subtilis.

In the present work, the antibacterial property of $C$. nutans appears to have justified its use for the treatment of wounds, which are contaminated through bacterial infections, and the pure compound that showed antibacte-

\section{TABLE IV}

Minimal inhibitory concentration (MIC) of 7-O- $\beta$-D-glucopyranosyl-nutanocoumarin against Staphylococcus aureus penicillinsusceptible and -resistant strains from clinical specimens

\begin{tabular}{lcccc}
\hline & \multicolumn{3}{c}{ MIC $(\mu \mathrm{g} / \mathrm{ml})^{a}$} \\
\cline { 2 - 5 } Microorganisms & No. & $50 \%$ & $90 \%$ & Range \\
\hline S. aureus penicillin-resistant & 10 & 125 & 125 & $62.5-125$ \\
S. aureus penicillin-susceptible & 6 & 500 & $>1000$ & $125->1000$ \\
\hline
\end{tabular}

a: $50 \%$ and $90 \%$, MICs at which 50 and $90 \%$ of the isolates are inhibited, respectively 
rial activity was identified as 7-O- $\beta$-D-glucopyranosylnutanocoumarin. Under the conditions employed here, 7$O-\beta$-D-glucopyranosyl-nutanocoumarin was active against $B$. subtilis and $S$. aureus, and virtually inactive toward E. coli and P. aeruginosa. The bactericidal effect of the isolated compound was more apparent against grampositive bacteria. Penicillin-resistant $S$. aureus strains seemed to be more sensitive to 7-O- $\beta$-D-glucopyranosylnutanocoumarin than penicillin-susceptible $S$. aureus. Our results indicate that in vivo data may be helpful in determining the potential usefulness of compounds from $C$. nutans for the treatment of infections caused by grampositive bacteria, including penicillin-resistant $S$. aureus.

\section{ACKNOWLEDGEMENT}

To Dr Luiz Carlos Marques (Departamento de Farmácia e Farmacologia, Universidade Estadual de Maringá) for the collection of the plant material. To Marinete Martinez for help in the experiments.

\section{REFERENCES}

Alves TMA, Silva AF, Brandão M, Grandi TSM, Smânia EF, Smânia Jr A, Zani CL 2000. Biological screening of Brazilian medicinal plants. Mem Inst Oswaldo Cruz 95: 367-373.

Badilla B, Mora G, Poveda LJ 1999. Anti-inflammatory activity of aqueous extracts of five Costa Rica medicinal plants in Sprague-Dawley rats. Rev Biol Trop 47: 723-727.

Barroso GM 1986. Sistemática de Angiospermae do Brasil, Universidade de Viçosa, Minas Gerais, 326 pp.

Bax R, Mullan N, Verhoef F 2000. The millennium bugs - The need for and development of new antibacterials. Int $J$ Antimicrob Agents 16: 51-59.

Cowan MM 1999. Plant products as antimicrobial agents. Clin Microbiol Rev 12: 564-582.
Heinrich M, Kuhnt M, Wright CW, Rimpler H, Phillipson JD, Schandelmaier A, Warhurst DG 1991. Lowland mixe indian medicinal plants: parasitological and microbiological evaluation and initial phytochemical study of Chaptalia nutans. Planta Med 57: A5-A6.

Leal-Cardoso JH, Fonteles MC 1999. Pharmacological effects of essential oils of plants of the Northeast of Brazil. An Acad Bras Cienc 71: 207-213.

Lorenzi H 1991. Plantas Daninhas do Brasil: Terrestres, Aquáticas, Parasitas, Tóxicas e Medicinais, Plantarum, Nova Odessa, São Paulo, 64 pp.

Martins ER, Castro DM, Castellani DC, Dias JE 1994. Plantas Medicinais, Universidade Federal de Viçosa, Viçosa, Minas Gerais, 220 pp.

Morton J 1981. Atlas of Medicinal Plants of Middle America, Charles Thomaz, Chicago, p. 154, 917.

Nakamura CV, Ueda-Nakamura T, Bando E, Melo AFN, Cortez DAG, Dias Filho BP 1999. Antibacterial activity of Ocimum gratissimum L. essential oil. Mem Inst Oswaldo Cruz 94: 675-678.

NCCLS-National Committee for Clinical Laboratory Standards. 1997a. Methods for Dilution Antimicrobial Susceptibility Tests for Bacteria that Grow Aerobically, Approved Standard M7-A4, Wayne, Pa.

NCCLS - National Committee for Clinical Laboratory Standards. 1997b. Methods for Determining Bactericidal Activity of Antimicrobial Agents, Document M26-T, Wayne, Pa.

Panizza S 1997. Plantas que Curam: Cheiro de Mato, IBRASA, São Paulo, p. 138-139.

Reitz R 1973. Flora Ilustrada Catarinense, Herbário Barbosa Rodrigues, Itajai, Santa Catarina, p. 50-57.

Truiti MCT, Sarragiotto MH 1998. Three 5-methylcoumarins from Chaptalia nutans. Phytochemistry 47: 97-99.

Villanova PA, Hackbarth CJ, Chambers HF 1989. Methicillinresistant staphylococci: detection methods and treatment of infections. Antimicrob Agents Chemother 33: 995-999. 